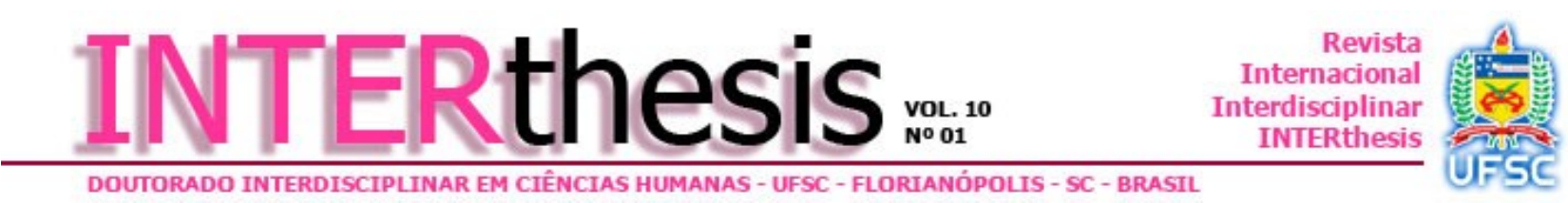

\title{
VIDA COTIDIANA Y MILITANCIA ARMADA EN LOS AÑOS '70 EN LA ARGENTINA: PROBLEMAS CONCEPTUALES E HIPÓTESIS DE LECTURA
}

\section{Resumen:}

Mariela Peller ${ }^{1}$

Este trabajo realiza un recorrido por una serie de autoras y autores que abren interrogantes respecto de las definiciones, alcances y límites de lo cotidiano con respecto a otras esferas de la existencia humana. En primer lugar, examino autores que desde el marxismo trabajaron la noción de vida cotidiana a partir de la categoría de alienación y su vínculo con la idea de revolución (Henri Lefebvre y Ágnes Heller). En segundo lugar, expongo las ideas de Michel de Certeau y de Norbert Lechner relativas a lo cotidiano entendido desde su oposición con lo no-cotidiano. Esta dicotomía es interesante porque a partir de ella se estructuran otras polaridades que conforman el espacio social y porque permite pensar la excepcionalidad del tiempo y el espacio de la militancia. En tercer término, presento las reflexiones de autoras provenientes de la teoría feminista y los estudios de género, fundamentales para el análisis de los cruces entre vida cotidiana y militancia, principalmente, porque es un objeto de estudio que se roza con la historia de las mujeres (Nelly Richard, Gayle Rubin, Joan Scott, Sylvia Molloy y Francoise Collin). Finalmente, estudio la utilidad de las conceptualizaciones de Judith Butler sobre la violencia y la precariedad de la vida para analizar los modos en que la violencia atravesó las vidas privadas de los militantes y sus familiares. En cada uno de los apartados subrayo ciertos problemas conceptuales y apunto hipótesis de lectura sobre los lazos entre vida cotidiana y militancia en los setenta.

Palabras-clave: Militancia. Vida cotidiana. Violencia.

"Este olvido de lo cotidiano - del hombre real - ha construido modelos que no resisten la historia".

(Héctor Schmucler, El testimonio de los sobrevivientes)

"Como si vivir se identificase con hacer y no hubiese otro tiempo que el de la historia". (Françoise Collin, Praxis de la diferencia)

\section{Presentación}

\footnotetext{
${ }^{1}$ Graduada em Sociologia pela Universidade de Buenos Aires, Buenos Aires, Argentina, docente do Curso de Sociologia nessa mesma casa de estudos e investigadora do Instituto Interdisciplinar de Estudos de Gênero, Buenos Aires, Argentina. E-mail: mariela_peller@hotmail.com
} 
Hace ya algunos años las ciencias sociales argentinas empezaron a interesarse por estudiar las transformaciones ocurridas en los campos de la sexualidad, la familia y las relaciones de género en las décadas del sesenta y setenta. Se pueden distinguir dos grupos de investigaciones, que si bien trabajan desde una perspectiva común (que a grandes rasgos podemos llamar "de género") difieren a nivel temático. Un primer grupo, aborda problemáticas referidas principalmente a los cambios en la vida privada y personal de las mujeres y los varones en la década del sesenta, comparando los nuevos modelos familiares, juveniles y sexuales con los vigentes en la década anterior (COSSE, 2010; FELITTI, 2012; COSSE, FELITTI y MANZANO (ed), 2010). Un segundo grupo, analiza la militancia de las mujeres y las relaciones de género en las organizaciones políticomilitares de los años setenta, cotejando los mandatos partidarios con las experiencias de militancia principalmente en lo relativo a los roles de género (GRAMMÁTICO, 2011; OBERTI, 2011; ANDÚJAR, 2009; GUGLIELMUCCI, 2006; MARTÍNEZ, 2009). ${ }^{2}$

La investigación que estoy realizando dialoga con las dos series de estudios, puesto que tiene por objetivo analizar las formas en que la organización de la vida cotidiana y familiar se anudó con la militancia armada en los años setenta, intentando comprender qué formas de politización de las esferas de lo privado y lo personal supusieron esos anudamientos.

Mi trabajo, a grandes rasgos, intenta comprender de qué modos se relacionaron las esferas de lo público y lo privado en la militancia de los setenta. Para ello estudio de qué formas se anudan diferentes tópicos relativos a esas esferas tanto en el discurso partidario como en los relatos personales de las y los militantes. En este sentido, un tema de interés es, por ejemplo, como la proletarización y la clandestinidad fueron prácticas de la militancia que necesariamente suponían una intervención sobre la vida privada de los militantes, aunque muchas veces esa intromisión no era evidenciada explícitamente. Los sentidos derivados de esas operaciones que no eran enunciadas, quedando más bien implícitas, es lo que me interesa indagar.

\footnotetext{
${ }^{2}$ Este agrupamiento borra las notables diferencias al interior de cada uno de los grupos (tanto en la perspectiva teórico-metodológica como en los resultados), principalmente del segundo; no es la finalidad de esta presentación analizar esas distinciones.
}

R. Inter. Interdisc. INTERthesis, Florianópolis, v.10, n.1, p. 37-64, Jan./Jul. 2013 
Algunas objeciones se han realizado a este tipo de objeto de estudio, discutiendo su interés y principalmente criticando las perspectivas metodológicas que suelen ir unidas a él. Las preguntas que nuclearían a esas objeciones serían las siguientes: ¿No es, acaso, inadecuado mirar la vida cotidiana y la familia para entender la militancia política y guerrera de los setenta? ¿Se pueden pensar los setenta desde lo afectivo y desde el género, cuando en el centro de los debates de aquellos años lo que circulaba era la política y la idea de revolución? Por supuesto, como la lectora ya imagina, la respuesta, desde ese punto de vista, es que no, no se puede. ¿Por qué?

En primer lugar, el problema es la noción de género, que sería inadecuada por anacrónica. Estas críticas afirman, equivocadamente, que durante los años sesenta y setenta la idea de "machismo" no circulaba entre las organizaciones políticas y armadas por lo que al analizarlas desde esa categoría una estaría ejerciendo una infidelidad hacia el objeto de estudio. ${ }^{3}$ En segundo lugar, una descripción de lo cotidiano y lo afectivo no permite comprender adecuadamente la política y la violencia de aquellos años; una lectura desde esas categorías ejercería, al fin y al cabo, nuevamente cierta infidelidad. Los trabajos de Beatriz Sarlo y de Hugo Vezzetti son un ejemplo de esta última postura.

Vezzetti dedica algunas páginas de su libro La violencia revolucionaria (2009) para criticar aquellos textos que desde el registro testimonial narran la vida cotidiana de las y los militantes. ${ }^{4}$ Para este autor:

\begin{abstract}
El sentido, el alcance de las prácticas milicianas, en el marco de un enfrentamiento definido como una guerra, no se desprende de una descripción de la vida cotidiana de los jóvenes radicalizados. La profundidad de la fractura que crecía y se manifestaba en esa contienda impiadosa no se deduce del anecdotario de los afectos, las pasiones y los vínculos que pueblan las evocaciones del período (VEZZETTI, 2009, p. 104).
\end{abstract}

Siguiendo esta argumentación, un análisis de la "cultura combatiente" no puede deducirse de la descripción de la vida cotidiana, porque esas descripciones

\footnotetext{
${ }^{3}$ Lo llamativo es que muchas veces son las mismas investigadoras que intentan pensar aquél período desde el género las que critican la posibilidad de esas lecturas.

${ }^{4}$ Vezzetti (2009) menciona los libros Mujeres Guerrilleras de Marta Diana (1996) y La Voluntad de Anguita y Caparrós (1997-1998) pero su crítica es extensiva a otros textos de compilación y análisis de relatos testimoniales; queda por analizar por qué se ensaña con el libro de Diana, quizás sea la primacía de voces femeninas lo que le parece lo más desacertado; siguiendo su lógica argumentativa, esa primacía no sería representativa de la militancia armada de los setenta.
}

R. Inter. Interdisc. INTERthesis, Florianópolis, v.10, n.1, p. 37-64, Jan./Jul. 2013 
hacen que el mundo de la vida y lo personal sepulte al mundo de la política. Si bien, para Vezzetti, las narraciones testimoniales evidencian la existencia de un doble escenario de conflictos entre la vida privada y las exigencias de la militancia, un sujeto es un militante sólo cuando está ocupando el espacio de la guerra y no lo sigue siendo en su casa cuando es marido y padre. A mí entender, estas objeciones reducen la militancia a la idea de guerra e igualan a los militantes con soldados, olvidando que las organizaciones armadas se propusieron algo más que ser un ejército guerrero.

Una crítica similar ya había realizado Beatriz Sarlo en Tiempo pasado (2005), donde cuestionaba aquellas intervenciones que, como el film Los rubios de Albertina Carri, leyeron la militancia de los setenta haciendo foco sobre la subjetividad y lo afectivo, en detrimento de la exhibición del espíritu de la época (fuertemente ideológico y político, según la autora), que permitiría comprender mejor aquellos años. Desde la mirada de Sarlo, los setenta -época marcada por lo político y lo ideológico- no pueden ser interpelados desde el género, la vida cotidiana y la sexualidad. Dos problemas teórico-ideológicos surgen de este tipo de argumento. El primero, referido a las definiciones, cruces y límites de lo político y lo ideológico, lo cotidiano y lo afectivo: ¿podemos seguir trabajando como si fuesen instancias separadas, opuestas y bien delimitadas unas de otras? El segundo, se refiere al problema del anacronismo. Pareciera que sólo se pueden formular preguntas que el pasado esté en condiciones de responder fácilmente y que en esas formulaciones sólo pueden utilizarse categorías vigentes en el pasado. Algo más bien imposible. Regresamos al pasado siempre desde el presente. $Y$ si bien el analista debe tener en cuenta la distancia temporal, la infidelidad que entraña cierto anacronismo permite, a mí parecer, realizar interpretaciones más productivas.

Para analizar la militancia armada de los setenta en Argentina no puede reducirse el estudio a las prácticas combatientes porque las propias organizaciones político-militares no hicieron una clara delimitación entre el territorio de la guerra y el espacio de la casa. La idea de "casa operativa" exhibe la existencia de ese enlace de espacios que implicaba entrecruzamientos y yuxtaposiciones que hicieron que, en muchos casos, el territorio de la casa fuese tomado por el de las armas. En esas ocasiones, la familia, lo doméstico y la presencia de los hijos funcionaron como "fachadas" contra el enemigo. Parecer una familia normal era parte de lo que los militantes debían exhibir para no ser identificados, en otras palabras, la puesta en 
escena de la familia y lo doméstico jugaba un rol específico en la militancia, no era algo al margen de las prácticas de "la guerra". 5

Tratando de encontrar conceptualizaciones que me permitan ir más allá de estas perspectivas y comprender las maneras en que se vieron imbricadas militancia y vida cotidiana en las organizaciones guerrilleras de los setenta, a continuación presento un recorrido por una serie de autoras y autores que abren interrogantes respecto de las definiciones, alcances y límites de lo cotidiano con respecto a otras esferas de la existencia humana. En cada uno de los apartados presento algunos problemas conceptuales y apunto hipótesis de lectura sobre los lazos entre vida cotidiana y militancia en los '70 en Argentina.

\section{Alienación y revolución de lo cotidiano}

Desde el marxismo varios autores han trabajado la noción de vida cotidiana a partir de la categoría de alienación. Aquí remitiré a las concepciones de Henri Lefebvre y Ágnes Heller.

Para Henri Lefebvre ${ }^{6}$ toda crítica de la vida cotidiana debe construirse alrededor de la noción de alienación; aún si se trata de realizar una crítica a la vida cotidiana en las sociedades socialistas. Justamente una de las cuestiones que más le interesa a Lefebvre es la crítica de esa vida cotidiana que muchos creen superada y desalienada por sostenerse sobre premisas socialistas. En suma, para Lefebvre el problema de lo cotidiano entronca con la cuestión del socialismo y su realización, tanto con la teoría marxista como con lo que ha ocurrido en los países socialistas. Si bien el primer tomo de Crítica de la vida cotidiana se publicó en 1947, el segundo

\footnotetext{
${ }^{5}$ Un ejemplo de este "uso" de lo familiar se halla en el caso de Felisa Barrionuevo de Ortiz analizado por Oberti (2011). Felisa, quien se incorporó a la militancia por sus hijos, narra cómo llevó adelante la logística de la Compañía de Monte con sus hijas de 11 y 12 años. "Ellas eran 'la fachada de la casa', se ocupaban de las compras, de las ropas, de llevar y traer mensajes e información, de preparar pertrechos y comida para los militantes. Felisa no 'subió al monte' pero organizó y sostuvo, junto con sus hijas, una serie de tareas fundamentales para el desarrollo de la guerrilla rural" (Oberti, 2011: 226).

${ }^{6}$ El primer tomo de Crítica de la vida cotidiana de Henri Lefebvre fue publicado en 1947 por la editorial Grasset (París) y el segundo en 1961 por la editorial L'Arche (París). Existe una traducción al español del segundo volumen publicada en México por Siglo XXI en 1972. Como no pude acceder a dicho volumen, aquí trabajo con secciones publicadas en la compilación Henri Lefebvre (1967), El marxismo sin mitos I, A. Peña Lillo Editor, Buenos Aires, que incluye parte de la publicación francesa de 1961.
}

R. Inter. Interdisc. INTERthesis, Florianópolis, v.10, n.1, p. 37-64, Jan./Jul. 2013 
tomo data de 1961, momento en que la URSS ya había comenzado a exhibir algunos rasgos que llevan a Lefebvre a sostener que en los países socialistas también existen contradicciones que crean formas nuevas de alienación. ${ }^{7}$

En este marco coyuntural es que le interesa comprender qué es lo que cambia de la vida con el socialismo, es decir, cómo interviene en la vida cotidiana de los individuos. Para Lefebvre no se puede definir la consumación del socialismo por el desarrollo de las fuerzas productivas, porque a lo que aspiran los hombres es a la "felicidad". "El socialismo (la sociedad nueva, la vida nueva) no puede definirse concretamente sino al nivel de la vida cotidiana, como un conjunto de cambios que llamamos lo vivido" (1967, p. 231).

En este sentido, una crítica de la vida cotidiana debe lograr separar los elementos vividos (nuevos, positivos) de una sociedad de las alienaciones (los elementos negativos). Entre aquellos aspectos vividos de la vida cotidiana que destaca Lefebvre, aquí mencionaré dos: el arte y el esparcimiento. Son elementos que lograrían comenzar a liberarnos de la alienación cotidiana si bien siempre dentro del ámbito de lo cotidiano.

El arte, particularmente el teatro épico de Bertolt Brecht, ha mostrado la extrañeza y el contenido épico de lo cotidiano, al evidenciar que aquello que nos parece tan familiar contiene a la vez lo banal y lo extraordinario. El método utilizado por Brecht, Verfremdungseffekt, planteaba ejemplos de la vida cotidiana, donde por medio de la puesta en escena de la conciencia de esa extrañeza que es para nosotros lo cotidiano, comenzaba, para Lefebvre, a liberar al espectador de la alienación. Las operaciones realizadas en las obras le otorgarían al espectador cierta conciencia de la alienación que le posibilitaría comenzar a liberarse de la misma. Si el teatro clásico imponía la identificación del espectador con el héroe y pretendía trascender la vida cotidiana exhibiendo una adhesión a las normas y valores admitidos, el teatro de Brecht produce el efecto contrario: el espectador no puede identificarse con el héroe porque debe tomar partido y asumir un juicio. De

\footnotetext{
${ }^{7}$ Luego en La vida cotidiana en el mundo moderno publicada en 1968 Lefebvre remarcará aún más esta crítica a los países socialistas. Para el autor la revolución se convirtió ella misma en cotidianidad: "institución, burocracia, organización de la economía, racionalidad productivista. Ante tales hechos, escribe Lefebvre, me pregunto si la palabra 'revolución' no ha perdido su sentido" ([1968]1884:51).
}

R. Inter. Interdisc. INTERthesis, Florianópolis, v.10, n.1, p. 37-64, Jan./Jul. 2013 
esa forma, se genera un diálogo con el espectador que lo desplaza del lugar pasivo que le tocaba ocupar en el teatro clásico. ${ }^{8}$

El esparcimiento sería otra forma en la que los individuos realizan espontáneamente la crítica de su vida cotidiana. Para Lefebvre la vida cotidiana implica tres aspectos que conforman un conjunto dialéctico: el trabajo, el esparcimiento y la vida familiar y "privada" (el autor es quien utiliza aquí las comillas). El individuo está determinado por la unidad y totalidad de estos tres aspectos.

A diferencia de las posibilidades del arte, que parecen mayores con respecto al desplazamiento del individuo de su posición alienada, la crítica de lo cotidiano realizada por medio de las actividades de ocio se mantiene dentro de los límites de lo cotidiano, es decir, no logra sustraerse del espacio de la alienación. Y ello principalmente porque la relación entre distracción y cotidianeidad no es simple: el esparcimiento es algo que no puede pensarse separado del trabajo. Por este motivo, las actividades de esparcimiento alcanzarían su máxima posibilidad de desalienar al individuo cuanto más se acerquen al arte, cuando puedan superar la actividad técnica. Ese encuentro con lo artístico, implicaría la búsqueda original de un estilo de vida. También de un arte de vivir y de una felicidad (1967: 224).

Algo de esta forma de entender la vida cotidiana desde las nociones de estilo de vida y arte de vivir se deja entrever cuando Lefebvre responde observaciones que le han realizado tras la aparición del primer tomo de su libro. Aquí, nos interesa, especialmente, su respuesta a las objeciones del historiador, para quien la crítica de la vida cotidiana entrañaría un retorno a lo anecdótico. Lefebvre contesta invirtiendo los términos, recusando él a la historia como ciencia: el discurso de la historia ha tenido como resultado la disociación del hecho histórico de ese otro aspecto de la historia y de lo humano que es lo cotidiano. Como lo cotidiano se relaciona con el tiempo cíclico (el de los días y las noches, las semanas y los meses, las estaciones y los años) no parece tener ningún atractivo para la historia, que se interesa por los grandes acontecimientos y se organiza alrededor de un tiempo lineal.

\footnotetext{
${ }^{8}$ Esta "desheroización" presente en las obras de Brecht parece interesarle a Lefebvre no sólo por los efectos producidos en el espectador de teatro sino porque discute con la tradición romántica en la que también queda incluida cierta forma de entender a los hombres por el socialismo. Lefebvre ha criticado a la literatura marxista, que mediante una retórica más bien simplista, comparaba al hombre nuevo socialista con las figuras del santo o del caballero, presentándolo como "enteramente positivo, heroico, sin miedo y sin reproche en el trabajo, la guerra y el amor", como "enteramente entregado a la sociedad (socialista) y encontrando en la entrega y el sacrificio el sentido de su individualidad". Así, el individuo era consagrado a la sociedad y se definía como determinado por ella (1967: 228-229).
} 
Como vemos, la vida cotidiana es más que el elemento humilde y sórdido de la vida en general (las repeticiones rutinarias, chatas e insignificantes). Es también el lugar y el tiempo donde lo humano se realiza. Por eso, Lefebvre organiza su trabajo alrededor de la idea de que "es en la vida cotidiana y a partir de ella como se realizan las verdaderas creaciones, las que producen lo humano y las producidas por los hombres en el curso de su humanización: las obras” (1967: 298).

\section{II}

Es, también, a partir de la noción de alienación que Ágnes Heller trabaja su idea de vida cotidiana. Para la autora, uno de los problemas a resolver por el pensamiento marxista revolucionario es el de la alienación de la cotidianeidad. Por ello se propuso elaborar un pensamiento conceptual para el cual una vida cotidiana no alienada sea posible. Un pensamiento que se entrelaza con la idea de socialismo, tal como fue entendido por Marx, y que implica la promesa de una forma de vida digna del hombre. ${ }^{9}$

Heller define a la vida cotidiana como "el conjunto de actividades que caracterizan la reproducción de los hombres particulares, los cuales, a su vez, crean la posibilidad de la reproducción social" (1998:19), es decir, es el conjunto de actividades por medio de las cuales los miembros de una sociedad reproducen esa sociedad y se reproducen a sí mismos.

Al igual que Lefebvre, Heller encuentra que la vida cotidiana tal como ella la encuentra cuando escribe, está alienada. Pero esa situación es posible de ser revertida. En "La teoría marxista de la revolución y la revolución de la vida cotidiana" ([1969]1994), analiza los vínculos entre revolución y vida cotidiana a la luz de una coyuntura en la que el mundo socialista se encontraba en crisis y el capitalismo había restituido y hasta reforzado la cotidianidad burguesa. Mientras que el socialismo no había llegado a configurar una forma de vida humanizada tal como se lo había propuesto, en los países capitalistas el desarrollo industrial generó cierta integración de las clases sociales y la adopción de formas de vida alienadas. Fue en esa coyuntura que el concepto de vida cotidiana asumió un interés creciente entre

\footnotetext{
${ }^{9}$ Aquí, presento las nociones elaboradas por Heller en Sociología de la vida cotidiana ([1970] 1998) y en un artículo previo donde sus ideas de encuentran sintetizadas, "La teoría marxista de la revolución y la revolución de la vida cotidiana" ([1969]1994).
}

R. Inter. Interdisc. INTERthesis, Florianópolis, v.10, n.1, p. 37-64, Jan./Jul. 2013 
varios pensadores de orientación marxista, que apostaron a esa noción para comprender los problemas que se planteaban a la praxis revolucionaria.

Heller recuerda que para Marx la revolución no se reducía a la toma del poder del estado por parte del proletariado revolucionario, sino que ése era sólo el primer paso hacia la abolición de la alienación, que implicaba toda una restructuración de la vida cotidiana. Desde esta perspectiva, la revolución sería la transformación de la vida cotidiana y de las formas de vida que sólo puede llevarse adelante por medio de la eliminación de la alienación.

Pero, ¿cómo eliminarla? Si Lefebvre encontraba en el arte y en el esparcimiento la capacidad de liberar al individuo de la alienación, en Heller es la idea de praxis la que nuclea esa posibilidad.

Como ejemplo de la posibilidad de una vida cotidiana no alienada, hace referencia a una época anterior a la civilización en la que sólo había una vida, la cotidiana. En ese tiempo el trabajo, la ciencia, el arte, la política, el derecho, la religión, la filosofía (espacios ahora pensados como no cotidianos) no eran espacios independientes. Esa independencia es producto del desarrollo de la propiedad privada y consecuentemente de la alienación.

Entonces, la alienación de la vida cotidiana no sería el resultado de las formas de actividad de la vida diaria sino de "la relación del individuo con esas formas de actividad" (1994, p.11). La relación es alienada porque no logra sintetizar las actividades del orden cotidiano y del no cotidiano en una unidad: no se refieren a la praxis humana total.

El problema del marxismo revolucionario es formular conceptualmente la posibilidad (e intentar la realización tentativa) de una vida cotidiana no alienada. Y esa formulación no debe esperar a la toma del poder del estado por parte del proletariado porque "la idea de que primero hay que abolir la alienación económica y política para seguidamente humanizar post festa las circunstancias y relaciones humanas cotidianas no deja de aparecérsenos como una idea no menos metafísica" (1994, p. 18). Al contrario, la modificación de las relaciones cotidianas es primordial porque, según Heller, primero se producen los cambios en la vida cotidiana y luego se empiezan a observar en la sociedad y en la historia; la vida cotidiana sería el "fermento secreto de la historia" (1998, p. 20). ${ }^{10}$

\footnotetext{
${ }^{10} \mathrm{Si}$ bien excede los límites de esta ponencia, no puedo dejar de mencionar la existencia de una serie de textos producidos por pensadores de la izquierda argentina en la década del sesenta referidos al
}

R. Inter. Interdisc. INTERthesis, Florianópolis, v.10, n.1, p. 37-64, Jan./Jul. 2013 
Como se desprende de mi presentación de los textos, los razonamientos de Lefebvre y Heller muestran que la noción de vida cotidiana comenzó a generar mayor interés cuando se hizo evidente que en los países socialistas los estilos de vida no se modificaban tal como se había pensado. Es fuerte el lazo que une a la idea de socialismo con la de transformación de la vida humana. Qué se entiende por esa transformación fue el problema que empezó a ocupar a muchos pensadores marxistas que estaban en desacuerdo con lo que ocurría en la URSS y otros países socialistas. Así, empezaron a revisar la teoría encontrando diferentes argumentaciones que podrían haber conducido a esa forma de entender la política. Volver sobre la categoría de alienación fue uno de los tópicos más importantes para estos dos autores. En ambos está presente el problema de las nuevas alienaciones producidas en los países socialistas como también de cuáles son las posibilidades de lograr liberarse de ellas.

Por su parte, Lefebvre, más crítico del pensamiento marxista, encontró algunos problemas en una tradición que exaltó las figuras del héroe y el hombre nuevo. Como también se refirió a los problemas derivados de un modo de entender la historia que sólo confía en los grandes acontecimientos y en el tiempo lineal y progresivo.

Creo que más allá de la utilidad de los pensamientos teóricos de estos dos autores y de la tradición a la que pertenecen, sus textos son un insumo indispensable, porque parte de sus argumentos y de las objeciones que realizan están en la base de las ideas y prácticas de la política revolucionaria de los setenta.

\section{El héroe y el hombre común}

Diversos análisis sobre la militancia en las organizaciones armadas de los años setenta han destacado la excepcionalidad del tiempo y el espacio de la guerra o la revolución como clave explicativa de las posiciones políticas y las acciones de la guerrilla (POZZI, 2004; CIRIZA y RODRIGUEZ AGÜERO, 2004/2005; MARTíNEZ, 2009). Desde esa perspectiva la guerra se opone a la dimensión de lo cotidiano y el héroe se constituye en la figura principal del período.

problema de la vida cotidiana en los que se incorporaba la noción de alienación. Cfr. Marcos Kaplan (1960), "Política y vida cotidiana"; León Rozitchner (1965), "La izquierda sin sujeto" en La Roda Blindada y Juan José Sebreli (1964), Buenos Aires: vida cotidiana y alienación.

R. Inter. Interdisc. INTERthesis, Florianópolis, v.10, n.1, p. 37-64, Jan./Jul. 2013 
En este apartado, expongo algunas ideas de Michel de Certeau y de Norbert Lechner relativas a lo cotidiano entendido desde su oposición con lo no-cotidiano. Me interesa esta dicotomía -cotidiano/no cotidiano- porque a partir de ella se estructuran muchas otras polaridades que conforman el espacio social.

Los trabajos de Michel de Certeau acercan la noción de lo cotidiano a la de "lo ordinario" y la oponen con las ideas de excepcionalidad y de heroicidad, rescatando la perspectiva de las prácticas de los "hombres ordinarios", "héroes comunes" o "antihéroes" "11. En La invención de lo cotidiano (1980) describe los modos de operación y los esquemas de acción de los usuarios (también denominados consumidores o dominados), quienes estarían supuestamente condenados a la pasividad y a la disciplina.

En contra de ciertas lecturas que ponen el foco en la pasividad, de Certeau propone que en sus acciones diarias los sujetos no sólo consumen sino que producen y fabrican. Esta producción "otra" es astuta, silenciosa, casi invisible, se encuentra dispersa pero insinuada en todas partes y no se expresa en productos propios sino en las maneras de utilizar los productos impuestos por el orden social dominante. Los dominados manipulan lo producido por otros, realizando una nueva producción que puede establecer una diferencia entre la producción primaria y la secundaria. Es una producción subrepticia, una forma de antidisciplina o subversión, en la que grupos e individuos ponen en juego su creatividad de forma dispersa y artesanal.

El lenguaje utilizado por el autor ya nos habla de este cambio de posición de la pasividad a la producción: las prácticas realizadas por sus hombres ordinarios son "artes de hacer" (leer, hablar, caminar, habitar, cocinar, circular, comprar, conversar). Estas "maneras de hacer" presentan una lógica de acción táctica, entendida como un cálculo que no puede contar con un lugar propio ni con una frontera que distinga al otro como una totalidad visible. La táctica sólo tiene el lugar del otro. No posee una base desde la cual capitalizar sus beneficios, preparar sus expansiones y asegurarse cierta independencia respecto a las circunstancias. Las prácticas de tipo táctico dependen del tiempo pero no lo dominan, y por ello deben estar atentas para aprovechar la ocasión y sacar provecho de situaciones y fuerzas ajenas, ya que no conservan nada de los triunfos que consiguen en un momento determinado. Estas

\footnotetext{
${ }^{11}$ De Certeau toma la noción de "hombre ordinario" del modo en que es utilizado por Sigmund Freud en El malestar en la cultura.
}

R. Inter. Interdisc. INTERthesis, Florianópolis, v.10, n.1, p. 37-64, Jan./Jul. 2013 
prácticas suponen un uso heterogéneo de productos no propios, en un espacio no propio. Pero mediante ese uso, que implica la implantación de otras reglas, pueden subvertir el sentido impuesto, produciendo de esta forma "una politización de las prácticas cotidianas" (DE CERTEAU, 1980: XLVIII).

En contraste, la lógica de la estrategia supone un cálculo de las relaciones de fuerzas, cálculo posibilitado cuando un sujeto de voluntad y de poder es susceptible de aislarse de su ambiente, postulando un espacio como lugar propio y autónomo que le sirve de base al manejo de sus relaciones respecto a una exterioridad. La racionalidad económica, política y científica se organiza sobre este modelo estratégico.

Michel de Certeau está interesado en describir esas prácticas del desvío o del escamoteo, que reintroducen en un espacio social dominado por la lógica estratégica, ciertas tácticas provenientes de otro tiempo o de otro espacio, engañando de esa forma al orden dominante, resignificando los sentidos que les son dados.

En suma, la propuesta de Michel de Certeau nos permite pensar en la capacidad que poseen los sujetos de forzar el orden dominante en sus prácticas cotidianas. La vida cotidiana implica todo un repertorio de "artes de hacer" a partir de las cuales los sujetos producen nuevas reglas y nuevos productos desplazándose de las posiciones imperantes. Ese desplazamiento es el que convierte a esas prácticas en políticas.

En el pensamiento de Norbert Lechner (1990) también encontramos la misma preocupación por pensar la vinculación entre vida cotidiana, sujeto y política. Para Lechner, el interés por el estudio de la vida cotidiana no puede separarse de la inquietud por comprender la constitución de los sujetos. Vida cotidiana, escribe el autor, es un concepto vago y equívoco, que designa un conjunto heterogéneo de fenómenos, escapando a las definiciones precisas; sin embargo, quizás sea en esa imprecisión donde resida su mayor atractivo: “¿Qué se entiende por vida cotidiana? Se trata de una noción multifacética, cargada de connotaciones generalmente polémicas, pero no explicitadas. La pregunta generalmente nos remite a otra: ¿qué sería la vida no-cotidiana?" (LECHNER, 1990, p. 46).

Oponiéndose a lo no cotidiano, lo cotidiano hace serie con lo rutinario y lo repetitivo (lo banal, lo común, lo insignificante), mientras que lo no cotidiano se refiere a la fiesta y a lo extraordinario, a lo único y a lo significativo. Pero más 
importante, es que esas rutinas que conforman la cotidianidad constituyen el ámbito de lo considerado natural y normal. En otras palabras, las actividades cotidianas de una sociedad definen criterios de normalidad, a partir de los cuales los individuos perciben y evalúan lo anormal, lo nuevo y lo problemático. Por ser el espacio donde se organiza esa percepción, es que lo cotidiano se torna campo de lucha política.

Como destaca Lechner, cuando se quiere investigar la vida cotidiana se suele recurrir a diferentes aspectos considerados por la sociología del trabajo, de la familia y de la sexualidad. Empero, referirse a la vida cotidiana implica algo más, supone un plus. Estudiar la vida cotidiana es enfocar una articulación que no puede ser reducida a una serie de fenómenos contrapuestos. Estudiar la vida cotidiana supone constituir el límite entre lo cotidiano y lo no-cotidiano como objeto de la investigación. El examen de ese límite posibilitaría la comprensión de los modos de estructuración de los pares de dicotomías que, estando normalizadas y naturalizadas, organizan el campo social.

Como sucedía también en las premisas del pensamiento de Lefebvre, Heller y de Certeau, en su apuesta por el estudio de la vida cotidiana, Lechner realiza una crítica contra una política asumida como acto heroico y sacrifico redentor que se enlaza con la idea de cambios radicales y rápidos. Estas objeciones les permitieron irse desplazando hacia una forma diferente de comprender el poder. Desde esta perspectiva: "Optar por un estudio de la vida cotidiana es optar por 'la rebelión del coro' en contra de una concepción heroica del mundo y de una vida social restringida al espacio público-político, de un modo de vida de espaldas a los medios de vida" (1990, p. 52).

\section{Sobre mujeres, heroínas y feminismo}

Si bien por otros caminos, las autoras que presento a continuación arribaron a conclusiones similares a las de los autores trabajados más arriba. En este apartado expongo reflexiones de diferentes autoras provenientes de la teoría feminista y los estudios de género que me parecen fundamentales para el análisis de los cruces entre vida cotidiana y militancia, principalmente, porque es un objeto de estudio que se roza con la historia de las mujeres. 
En su texto "Género", entrada para un diccionario de sociología de la cultura, Nelly Richard (2002) compendia los aportes de la teoría feminista y los estudios de género a las ciencias sociales. Allí sostiene que la tesis del movimiento feminista "lo personal es político" ${ }^{12}$ sintetiza, no sólo, la crítica del feminismo a la división de esferas entre lo público y lo privado, sino también, la ampliación que le otorgó al concepto de poder al anudarlo con la noción de subjetividad.

El feminismo denunció la reducción de lo económico a lo productivo y la consiguiente exclusión de la reproducción (maternidad, hogar, familia) del campo de visibilidad de los mecanismos de poder, que estaba presente en otras teorías, incluyendo a cierto marxismo. Si el marxismo dejaba fuera de consideración política y teórica a los escenarios de la vida cotidiana y familiar, el concepto género abrió el campo para reflexionar sobre las implicancias de esta división jerarquizada del espacio social, en la cual lo público se asocia con lo masculino (y también con acción/ razón/ poder/ ciudadanía/ política/ abierto/ estado/ soberanía/ universal/ general/ cultura) y lo privado con lo femenino (como también con cuerpo/ domesticidad/ afectividad/ cerrado/ deseo/ necesidad/ particular/ naturaleza). A partir de la puesta en duda de esta división de esferas, el feminismo se refiere a las relaciones, límites y dependencias de cada uno de los polos de estas dicotomías, cuestionando las series.

Otro de los aportes centrales del feminismo puede rastrearse en el texto de Gayle Rubin "El tráfico de mujeres. Notas sobre la 'economía política' del sexo" ([1975] 1998), donde la autora conforma el concepto de sistema de sexo/género. Definido como un sistema de producción de seres humanos, que transforma el sexo biológico en productos de la actividad humana, es decir, en género cultural, dicho concepto permitió cuestionar a quienes recurrían a las fuerzas económicas para explicar la opresión de las mujeres.

\footnotetext{
${ }^{12}$ Como recuerda July Cháneton (2007) la consigna fue acuñada por Carol Hanisch en un artículo con ese título publicado en 1971 en la revista neoyorquina The Radical Therapist. Cháneton destaca la "eficaz economía simbólica" del enunciado que hace que continúe "vigente como premisa teórica que interfiere en los modelos clásicos de pensamiento político. Contiene una reformulación de la conceptualización del poder, entendido ahora más allá del estado y sus instituciones, al tiempo que denuncia el dispositivo de asignación de espacios sociales sexuados jerarquizados que son parte decisiva de la organización económica y cultural en la modernidad (público-productivo-masculinojerarquizado con respecto al privado-reproductivo-femenino). La novedad consistía en redefinir la experiencia personal y 'privada' en sus determinaciones sociales y culturales, pero focalizando la dimensión política de las relaciones -no sólo estructurales sino también individuales- entre los sexos" (CHÁNETON, 2007, p. 27).
} 
Este artículo de Rubin fue escrito en el contexto de la temprana segunda ola del feminismo, cuando el paradigma dominante de ese momento entre los intelectuales progresistas era el marxismo. Como muchas otras feministas de aquella época, Rubin establece una relación conflictiva con el marxismo: si bien utiliza muchos de sus conceptos también marca una fuerte separación. Para esta autora es imposible comprender la diferencia sexual y la opresión de las mujeres desde esta tradición y por ello decide remitirse a conceptos de la antropología estructuralista y el psicoanálisis.

Con la intención de generar un concepto que permita "ubicar" la opresión de las mujeres en otro territorio que el de la economía o el de la biología, Rubin cuestiona los usos de otras dos categorías: modo de reproducción y patriarcado. Por un lado, la idea de "modo de reproducción" que utilizan algunas feministas es errónea porque supone un ámbito de lo social que refiere simplemente al momento reproductivo del "modo de producción". En cambio, la categoría de sistema de sexo/género incluye mucho más que las relaciones de procreación biológicas y también permite pensar "producciones" (de sujetos, de identidades, de instituciones, etc.) dentro del campo sexual. Por otro lado, el concepto de "patriarcado", utilizado por las feministas radicales, referiría a una forma específica de sistema de sexogénero, ya que remite a un tipo específico de dominación. En suma, la ventaja del concepto sistema de sexo- género es que se presentaría como una noción "neutral" que permitiría conceptualizar a la opresión como algo modificable.

Si bien Rubin construye este concepto para remitir a aquél espacio de lo social referido a la sexualidad y al género, no supone su desconexión respecto de otras esferas de lo social. Existe una interdependencia recíproca entre el sistema de sexo/género y los sistemas económicos y políticos. Cualquier análisis está incompleto si olvida esta interconexión pero también si subestima el significado de cada una de estas dimensiones de una sociedad.

II

Como destaqué en el punto anterior, los estudios de género no son estudios referidos sólo a las mujeres ni a la familia, ni a los niños. Lo que intentan, en cambio, es comprender el funcionamiento del poder en el sistema de sexo-género y la constitución de subjetividades e identidades de género. En "El género: una categoría útil para el análisis histórico" (1996) Scott realiza una crítica sobre el concepto de 
género: intenta quitarle su uso restringido a un campo específico de temas para demostrar que atraviesa todos los ámbitos de la vida social y de la historia. Scott se posiciona contra dos ideas ampliamente difundidas en aquél momento: 1) la idea de que las mujeres tienen su propia historia separada de la historia de los hombres, 2) la idea de que la historia de las mujeres es sobre el sexo, la familia y los niños ("cosas relacionadas con mujeres") y debe separarse de la historia política y económica. En cambio, Scott realiza una definición de género doble: por un lado, como un elemento constitutivo de todas las relaciones sociales (que incluye símbolos, normativas, nociones específicas e identidades) y, por otro, como un campo primario en el que se articula el poder, ejerciendo una función legitimadora y constituyéndose en un modo de decodificar significados sociales, es decir, que es una mirada específica sobre lo social.

Esto supone que una perspectiva de género no se define por los temas que se analizan (más o menos femeninos, más o menos privados, más o menos personales, ligados a la familia, a las mujeres), no se caracteriza por el tipo de objetos que se estudian (por el qué se analiza) sino que se construye a partir del modo de interpretación de esos objetos (del cómo se mira). Una perspectiva de género es más bien aquella donde está en juego el modo en que opera esa mirada sobre los fenómenos culturales. Desde la crítica literaria, Sylvia Molloy propone:

\footnotetext{
usar el género como categoría dinámica y relacional, no como categoría estanca, para hacer lecturas no simplemente en el género sino desde el género. Esa necesidad es tanto más crucial cuanto que el género, lejos de ser una perspectiva crítica anacrónica desde donde leer el pasado, está muy presente, como preocupación en los comienzos mismos de la modernidad latinoamericana (MOLLOY, 2010, p. 203).
}

Desde estas perspectivas, propongo poner a trabajar la categoría de género en lo que se refiere al pasado pero también en lo que se refiere al lenguaje, haciendo hincapié en lo que los textos dicen y esconden sobre el género y también en las posiciones enunciativas asumidas en los discursos, posiciones que siempre son sexuadas.

\section{III}

En un texto bello, "Historia y memoria o la marca y la huella" ([1995] 2006), Françoise Collin analiza los límites del saber histórico. Particularmente, se refiere a 
las modalidades por medio de las cuales la historia de las mujeres y la historia feminista intentan otorgarles a las mujeres un lugar en la historia en general y en su historia, al analizar los procesos por los cuales han sido sustraídas de los espacios de poder.

El problema para Collin es que esos procedimientos ponen en evidencia que la historia de las mujeres comparte con la historia en general una concepción del sujeto y del tiempo. Desde estas disciplinas sólo merecería entrar en la historia y llamarse humano aquél que ha actuado y ha cambiado el mundo, aquél que con su acción ha dejado una marca que la historia pueda reconocer. Así, el tiempo es pensado sólo en términos de cambio y de progreso y el sujeto es siempre un sujeto de la acción heroica.

En cambio, Collin intenta rescatar otro territorio de lo humano. Para esta autora, el actuar no resume la totalidad de la experiencia humana y el tiempo no es sólo historia y transformación. Existe otra forma del devenir, existen huellas irreductibles a las marcas legibles por la historia.

Esta dimensión del "para nada", de "lo inútil", de "la pérdida" es desatendida por la historia (y por la historia de las mujeres), justamente por su incapacidad de dejar marcas. Esa dimensión refiere al gesto que no toma la forma de un acto y que por la tanto no puede acumularse ni contabilizarse: la "simple repetición", el "simple ejercicio de la vida". Para el feminismo, escribe Collin, ignorar esta dimensión de lo humano entraña una paradoja, porque abre una brecha entre las mujeres feministas como agentes de cambio y las mujeres comunes que no se plantean (y muchas veces no pueden) cambiar el mundo. Un feminismo que cree que "mujeres" son sólo aquellas que actúan adquiriendo capacidad política estaría repitiendo aquello que ha denunciado del patriarcado: valorar sólo lo que produce, lo que puede, lo que hace, lo que transforma, en suma, lo que hace historia.

Se quiera o no, lo que se reactiva así es toda una filosofía del 'sujeto' y de lo que en cada una, y en cada uno, es sujeto, así como una historia de héroes y heroínas (...). ¿La historización de las mujeres culminaría, entonces, en un panteón de mujeres ilustres, adosado al panteón de los hombres ilustres? (COLLIN, 2006,'p.120)

En un espacio otro respecto a la historia compuesta por heroínas, héroes y panteones, la dimensión del para nada cobra relevancia en el pensamiento de Collin porque es la que conforma -más profundamente que la dimensión de lo útil- las 
relaciones humanas. Lo que se disipa, lo invisible, lo impalpable forman parte de esa dimensión otra (no exactamente opuesta, sino otra) con respecto a lo útil, a lo eficaz, a lo que actúa, a lo que gana, a lo que transforma, a lo que deja marca. ${ }^{13}$

Si bien Collin no pretende negar el procedimiento histórico que busca reinscribir las marcas dejadas por las mujeres que la historia en general desconoce, cree que esas marcas hablan sólo de una parte del pasado. Una verdadera historia de las mujeres no es ni la historia de las feministas ni la historia de las mujeres que han realizado cambios, un pensamiento feminista no puede dejar de lado la herencia de aquellas mujeres que no ha podido manifestarse ni por la acción ni por la palabra.

El pensamiento sobre la importancia de la dimensión del para nada y sobre la huella elaborado por Collin es inspirador para pensar el lugar ocupado, principalmente, por las mujeres militantes pero también por los militantes en general en los años setenta en Argentina. Es una posibilidad para alejarse de las figuras heroicas y acercarse a ese pasado desde otras coordenadas. Las mujeres militantes fueron mujeres que actuaron, mujeres guerrilleras, mujeres combatientes. Sería interesante poder mirarlas también desde el ángulo del "para nada". Dimensión de lo cotidiano muy presente en la vida de esas mujeres "heroicas".

La mayoría de las investigaciones sobre la militancia de las mujeres en los setenta pone el foco principalmente sobre las marcas, mostrando los "avances" de estas mujeres con respecto a generaciones anteriores y a sus coetáneas. El pensamiento de Collin nos permitiría poder percibir también algunas huellas:

\begin{abstract}
No se trata de elegir entre el registro de la acción innovadora, como lo único que haría al hombre o a la mujer dignos de este nombre, y el registro del gesto, destinado a su disipación, de elegir entre lo que deja marca y lo que deja huella, entre la historia de lo que se nombra y la memoria de lo innombrable, entre lo dominable y lo indominable; esto sería prorrogar la vieja alternativa dualizante de los sexos, la de lo masculino progresivo y lo femenino repetitivo (COLLIN, 2006, p.124).
\end{abstract}

\title{
Vidas precarias. La vida cotidiana atravesada por la violencia
}

\footnotetext{
${ }^{13}$ Collin destaca que si bien esta dimensión de la vida humana ha sido olvidada o abandonada por la teoría feminista puede, sin embargo, hallarse en ciertas obras literarias, por ejemplo, en los textos de Marguerite Duras. Quizás toda obra de arte ponga en juego "una memoria que recoge el olvido de lo inmemorial" (COLLIN, 2006, p. 120) y que desde allí es capaz de escabullirse a la construcción de la historia y del tiempo en términos de cambio.
}

R. Inter. Interdisc. INTERthesis, Florianópolis, v.10, n.1, p. 37-64, Jan./Jul. 2013 
Un tema importante para el análisis de la militancia armada de los setenta en Argentina se refiere a los modos en que la violencia atravesó las vidas privadas de los militantes y sus familiares. En este apartado intento enmarcar algunas de las conceptualizaciones de Judith Butler sobre la violencia y la precariedad de la vida que me parecen interesantes para reflexionar sobre algunas dimensiones de la militancia de los setenta: 1) las implicancias que tuvieron para los militantes haber tenido la capacidad de matar, haber matado y/o haber estado en exposición a la muerte propia o ajena; 2) los modos en que fue tramitado el miedo experimentado por los militantes, drama de los afectos inseparable del problema de la muerte propia y de los seres queridos; y 3) la exposición a la precariedad y a la violencia que implicaron los usos cotidianos y revolucionarios de los cuerpos, sobre todo para las mujeres y sus hijos (partos, mudanzas, escuelas, falta de un lugar propio, pérdida de otros lazos sociales).

En Vida precaria (2006) y Marcos de guerra (2010) Butler presenta una serie de artículos que intentan aportar herramientas para comprender el contexto mundial actual regido por múltiples guerras. Son textos que, como la mayoría de los producidos por esta autora, entrecruzan la ética con la filosofía y la política, tratando de responder a la pregunta por las formas en que la violencia atraviesa las vidas privadas en la actualidad. Sin embargo, estos textos no sólo abordan la cuestión de la precariedad de las vidas en esos contextos específicos de guerra sino que construyen conceptos que posibilitan pensar más allá, puesto que se sostienen sobre un modo de comprender la conformación de los cuerpos, que puede resultar útil para el análisis de otros objetos.

Para Butler la precariedad de la vida es tanto el origen como el resultado de que toda ontología corporal deba ser entendida como una ontología social. Desde esta perspectiva, el cuerpo es un fenómeno social, dependiente del afuera -del Otroy de ello deriva su vulnerabilidad pero también su existencia.

En "Violencia, duelo, política" (2006) Butler sostiene que todo sujeto convive con una vulnerabilidad corporal original respecto del Otro, causada por nuestra interdependencia primaria con respecto a esos otros que con su sostén también nos dan la posibilidad de existir. Este modo de entender al sujeto como habilitado por la sujeción es un tópico central del pensamiento de Butler, que pone en duda la idea de un sujeto autónomo y soberano. 
La precariedad y la vulnerabilidad de nuestras vidas son consecuencia, entonces, de que nuestros cuerpos son dependientes del Otro tanto en su sujeción como en su habilitación. De ese origen en la precariedad, un origen que pone en evidencia que podríamos no haber existido o podemos dejar de existir de un momento a otro (dice Butler que nacer es nuestro primer acto precario) se derivan los usos y abusos posteriores que podamos hacer (nosotros y los otros) de la violencia. La violencia siempre actualiza y explota cierto lazo primordial que poseemos con ella, por ser susceptibles de recibirla a causa de nuestro estar expuestos a los otros, de nuestra vulnerabilidad.

Estas premisas sobre la vulnerabilidad y la precariedad son inseparables de un modo de comprender al cuerpo, de una ontología corporal específica. Butler encuentra que muchos discursos sociales (sobre todo en lo que hace a las guerras) generan concepciones excluyentes y normativas de lo humano, que conducen a una distribución diferencial del valor de las vidas. Así, nos encontramos con que hay vidas que vale la pena ser vividas, que son merecedoras de duelo y de llanto y otras que no. Si bien ella describe y critica esta situación de distribución diferencial de lo humano no quiere situarse desde una ontología de lo humano. Prefiere trabajar con una idea de lo humano como una cualidad (en distinción a una idea de Humanidad que implicaría una naturaleza humana), donde se constituyen grados de lo humano (más o menos humano, inhumano, humanamente inconcebible).

En "Vida precaria, vida digna de duelo" (2010) introducción a Marcos de guerra, Butler remarca que lo que está intentando hacer es pensar una nueva ontología corporal.

\begin{abstract}
El 'ser' del cuerpo al que se refiere esta ontología es un ser que siempre está entregado a otros: a normas, a organizaciones sociales y políticas que se han desarrollado históricamente con el fin de maximizar la precariedad para unos y de minimizarla para otros. No es posible definir primero la ontología del cuerpo y referirnos después a las significaciones sociales que asume el cuerpo. Antes bien, ser un cuerpo es estar expuesto a un modelado y a una forma de carácter social, y eso es lo que hace que la ontología del cuerpo sea una ontología social (BUTLER, 2010, p. 15).
\end{abstract}

En ese texto hace una importante distinción entre precariedad (precariousness) y precaridad (precarity). La precariedad implica que vivimos socialmente y que por eso nuestra vida depende siempre de los otros. Estamos expuestos permanentemente a esos otros, que en muchos casos nos permanecen 
anónimos. La precariedad supone que podemos morir, por lo que para sobrevivir a los daños y a la muerte necesitamos múltiples cuidados: cobijo, alimento, redes de sociabilidad, trabajo, entre otros. Todo esto significa que: "Vivir es siempre vivir una vida que se halla en peligro desde el principio y que puede ser puesta en peligro o eliminada de repente desde el exterior y por razones que no siempre están bajo el control de uno."(2010: 52) Para Butler asumir esta precariedad humana común podría, en lugar de ser aquello que nos enfrenta, resultar la base para la conformación de una comunidad política, lo que, sin embargo, no niega la existencia de una distribución geopolítica desigual del dolor y la vulnerabilidad ni supone una noción común de lo humano. Para Butler si bien podemos pensar en la existencia de una vulnerabilidad humana generalizada causada por una condición de despojo inicial frente al otro, existen contornos culturales que delimitan lo humano, esas vidas que pueden ser lloradas y que son merecedoras de duelo.

Por otra parte, precaridad es una noción más política. Designa la condición políticamente inducida de precariedad, en la que ciertas poblaciones sufren la falta de redes sociales y económicas y están, por lo tanto, más expuestas a los daños, la violencia y la muerte. La precaridad es una distribución diferencial de la precariedad pero producida políticamente.

Para finalizar este apartado, quisiera esbozar aquí algunas hipótesis de lectura sobre la militancia de los setenta a partir de las ideas de Butler. En primer lugar, podría entenderse que, al militarizar parte de la vida cotidiana, las organizaciones armadas argentinas maximizaron la precariedad de la vida militante, es decir, produjeron una distribución diferencial de la precaridad. Esa maximización quizás haya sido el resultado de un olvido o de la necesidad de ignorar la precariedad de la vida (y la necesidad de su protección) para que muchas de las normas de los partidos pudieran seguir circulando.

Otra línea de lectura se vincula con la construcción de vidas con mayor valor que otras al interior de la militancia. ¿Qué vidas fueron construidas como protegibles y cuáles no? ¿Qué vidas tuvieron más valor, las de los dirigentes, las de las mujeres, las de los niños? Indudablemente existió cierta distribución diferencial de la precariedad, las normas asignaban reconocimiento diferencial del valor de las vidas. Por ejemplo, mucho se ha cuestionado el modo en que se resolvió la fuga del penal 
de Rawson, que implicó que los dirigentes de las organizaciones armadas pudieran salir del país hacia Chile mientras otros militantes fueron finalmente fusilados. ${ }^{14}$

\section{Consideraciones finales}

Como epígrafe de este trabajo presenté unas palabras de Héctor Schmucler (1980) publicadas en Controversia, una revista editada por exiliados argentinos en México. ${ }^{15}$ En ese texto, escrito en plena dictadura argentina, Schmucler analiza testimonios de sobrevivientes de centros clandestinos de detención a partir de los cuales intenta comprender el cómo y por qué de la derrota de la guerrilla. Schmucler encuentra en esos relatos los ecos de una destrucción subjetiva anterior a la captura y a la tortura, que habría sido el corolario de un modo específico de entender la política.

Una política entendida como técnica, como una parte de la vida cotidiana, como un campo diferenciado del quehacer humano, es una política enmarcada dentro de una concepción burguesa. Así, la política revolucionaria de los setenta se mantuvo bajo la égida de aquellas lógicas del poder y la política que deseaba modificar. En contra de esta concepción que fragmenta y desarticula vida y política, el autor propone una idea de política entendida como parte de la vida cotidiana, lo que significa pensar "la vida como política".

Me interesa volver sobre este texto porque ensambla las dos preocupaciones que organizaron mi escrito: el problema de la vida cotidiana y el de los modos de la política revolucionaria en los setenta. Escribe Schmucler sobre y en aquellos años:

\footnotetext{
${ }^{14}$ En el penal de máxima seguridad de Rawson, donde se encontraban detenidos varios de los principales dirigentes guerrilleros de aquella época, las organizaciones armadas Montoneros, ERP y FAR coordinaron un plan de fuga de 100 militantes. El 15 de agosto de 1972 luego de tomar el penal, un supuesto malentendido de aquellos que debían pasar a buscar a los prisioneros hizo que sólo pudieran escapar los seis máximos dirigentes. Otros diecinueve militantes pudieron huir en taxis y remises, pero llegaron al aeropuerto de Trelew cuando el avión que debía sacarlos del país ya había partido. Estos diecinueve militantes fueron trasladados a la base Almirante Zar (a pesar de que se les había prometido llevarlos nuevamente al penal), y allí luego de varios días de ser torturados, la madrugada del 22 de agosto fueron fusilados. Tres de ellos se salvaron, aunque luego del golpe militar de 1976, fueron desaparecidos. Roberto Pittaluga (2008) realiza un interesante análisis de los significados políticos de la fuga del penal de Rawson a través del estudio de dos documentales realizados como tesis de licenciatura en la Facultad de Ciencias Sociales (UBA): Prohibido dormir (2004) de Paula Bassi y Diego Pauli y JP Rawson. Crónica de una militancia (2007) de Nahuel Machesich.

15 Alejandra Oberti considera este artículo como un "testimonio paradigmático" porque habla del pasado incorporando tanto su experiencia como las voces de otros, habla en nombre propio y en el de aquellos que ya no pueden hacerlo. Pero también porque vuelve a ese pasado de manera descentrada y desobediente, desplazándose al narrar (OBERTI, 2008).
}

R. Inter. Interdisc. INTERthesis, Florianópolis, v.10, n.1, p. 37-64, Jan./Jul. 2013 
La izquierda olvida, negándose a sí misma, las preguntas centrales que le darían sentido: de qué nueva manera se relacionan los hombres entre sí, cómo cambia la relación de cada hombre con su cuerpo, cómo se modifica el vínculo de los seres humanos con la naturaleza, en fin qué nueva cultura se propone. (1980:5)

Las preguntas planteadas por Schmucler resumen las preocupaciones teórico-políticas que aparecieron en el recorrido que propuse en este trabajo. De las diferentes perspectivas presentadas me gustaría subrayar algunos puntos a modo de cierre.

En primer lugar, podemos concluir que analizar la vida cotidiana sería otra cosa que mirar lo anecdótico, lo ordinario, lo común para contraponerlo con la historia excepcional y heroica de la lucha armada. Analizar la vida cotidiana implicaría correr el foco de las oposiciones para trabajar en las articulaciones de espacios que conforman lo que luego vivimos día a día como la norma (de los cuerpos, de los sujetos, de la política).

En segundo lugar, no se pude perder de vista la interdependencia de los espacios de lo social, que exhibe la ineficacia de las explicaciones reduccionistas para comprender cualquier tipo de discurso y de práctica. Es necesario desplazarse de interpretaciones que fragmentan los espacios sociales y los modos de comprender al sujeto para pensar las experiencias en su totalidad, intentando articular aquello que se nos presenta como independiente. En este sentido, sostener el carácter liminal del concepto de vida cotidiana dentro del entramado social es una premisa interesante.

Tercero, el valor de lo cotidiano en la transformación de la sociedad y los sujetos, es decir, su carácter político. La importancia de ese vínculo entre política y vida cotidiana, me conduce a pensar que el modo en que lo cotidiano es concebido hace al quid de los alcances revolucionarios de una política.

Cuarto, la necesidad de poner en cuestión las formas en que el analista conforma su objeto. ¿Estudiar los setenta es examinar la vida de mujeres y hombres heroicos? ¿Qué sentidos les estamos adjudicando a sus prácticas cuando las conformamos desde antes de analizarlas con esas adjetivaciones? ¿Qué nos perdemos al buscar sólo aquello que deja marca? En suma, ¿qué idea de sujeto sostiene nuestra investigación? 
Y finalmente, el reconocimiento de la precariedad de la vida conduce a poner en el centro del análisis la vinculación entre cuerpo, política y vida cotidiana. Porque muchas veces olvidada y menospreciada por su familiaridad, la cotidianeidad no hace otra cosa que organizar y distribuir de modo diferencial el valor de los cuerpos en el tiempo y el espacio. Que es lo mismo que decir que hace política. 


\title{
VIDA COTIDIANA E MILITÂNCIA ARMADA NOS ANOS '70 NA ARGENTINA: PROBLEMAS CONCEITUAIS E HIPÓTESES DE LEITURA
}

\section{Resumo:}

Este trabalho faz um percurso por uma série de autores e autoras que levantam questões sobre definições, alcance e limites do cotidiano em relação a outras esferas da existência humana. Primeiro, examino autores que partindo do marxismo trabalharam a noção da vida cotidiana a apartir da categoria de alienação e de sua ligação com a ideia de revolução (Henri Lefebvre e Agnes Heller). Em segundo lugar, exponho as ideias de Michel de Certeau e Norbert Lechner, relativas ao cotidiano entendido em oposição ao não-cotidiano. Esta dicotomia é interessante porque a partir dela se estruturam outras polaridades que conformam o espaço social e porque permite pensar a excepcionalidade do tempo e espaço de militância. Terceiro, apresento as reflexões de autoras provenientes da teoria feminista e dos estudos de gênero, fundamentais para análise dos cruzamentos entre a vida cotidiana e militância, principalmente porque é um objeto de estudo que entra em atrito com a história das mulheres (Nelly Richard, Gayle Rubin, Joan Scott, Sylvia Molloy e Françoise Collin). Por fim, estudo a utilidade de conceituações de Judith Butler sobre a violência e a precariedade da vida para analisar as formas em que a violência atravessou as vidas privadas dos militantes e suas famílias. Em cada um dos parágrafos enfatizo certos problemas conceituais e aponto hipóteses de leitura sobre as ligações entre a vida cotidiana e militância nos anos setenta.

Palavras-chave: Militância. Vida cotidiana. Violência.

\section{EVERYDAY LIFE AND ARMED MILITANCY IN ARGENTINE DURING THE SEVENTIES: CONCEPTUAL PROBLEMS AND READING HYPOTHESIS}

\begin{abstract}
:
This paper analyzes a number of authors who raise questions about the definitions and boundaries of the everyday life in relation to other areas of human existence. First, I examine some Marxist authors who have worked the notion of everyday life from the category of alienation and its link with the idea of revolution (Henri Lefebvre and Ágnes Heller). Secondly, I discuss the ideas of Michel de Certeau and Norbert Lechner, who understood the category of the everyday life in his opposition to the non-daily life. This dichotomy is interesting because it structured many other polarities that build the social space and because it's useful to think about the exceptionality of time and space of the armed militancy. Third, I present the reflections of different feminist authors that are essential for the analysis of the ties between everyday life and militancy, mainly because it's an object of study that touches the women's history (Nelly Richard, Gayle Rubin, Joan Scott, Sylvia Molloy and Francoise Collin). Finally, I study the usefulness of Judith Butler's conceptualizations on violence and precariousness of life to analyze the ways in which violence broke through the private lives of militants and their families. In each of the sections, I present some conceptual problems and mention hypotheses about the links between everyday life and activism in the seventies.
\end{abstract}

Keywords: Militancy. Daily life. Violence. 


\section{Referencias}

ANDÚJAR, Andrea. El amor en tiempos de revolución: los vínculos de pareja de la militancia de los 70. Batallas, telenovelas y rock and roll. In: ANDÚJAR, A.; D'ANTONIO, Debora Gil; LOZANO, F. GRAMÁTICO, K.; (Et al.). De minifaldas, militancias y revoluciones. Exploraciones sobre los 70 en Argentina. Buenos Aires: Ediciones Luxemburg, 2009.

BUTLER, Judith. Vida precaria. El poder del duelo y la violencia. Buenos Aires: Paidós, 2006.

. Marcos de guerra. Las vidas lloradas. Buenos Aires: Paidós, 2010.

CIRIZA, Alejandra; RODRIGUEZ AGÜERO, Eva. Militancia, política y subjetividad. La moral del PRT-ERP. Políticas de la memoria, N 5 , Buenos Aires, CeDInCl. $2004 / 2005$.

COLLIN, Françoise. Historia y memoria o la marca y la huella en Praxis de la diferencia. Barcelona: Icaria, [1995] 2006.

COSSE, Isabella. Pareja, sexualidad y familia en los años sesenta. Una revolución discreta en Buenos Aires. Buenos Aires: Siglo XXI, 2010.

COSSE, I.; FELITTI, K.; MANZANO, V. (ed.). Los '60 de otra manera. Vida cotidiana, género y sexualidades en la Argentina. Buenos Aires: Prometeo, 2010.

CERTEAU, Michel De. La invención de lo cotidiano I. Artes de hacer, México: Univ. Iberoamericana, 1980.

FELITTI, K. La revolución de la píldora. Sexualidad y política en los sesenta. Buenos. Aires: Edhasa, 2012.

RUBIN, Gayle. El tráfico de mujeres: notas sobre la 'economía política' del sexo. In: NAVARRO, M.; STIMPSON, C. (Comp.). ¿Qué son los estudios de mujeres?. Buenos Aires: FCE, [1975]1998.

GRAMMÁTICO, Karin. Mujeres montoneras. Una historia de la Agrupación Evita, 1973-1974, Buenos Aires: Ediciones Luxemburg, 2011. 
GUGLIELMUCCI, A. Dar la vida y la muerte por la revolución. Moral y política en la praxis militante. Lucha armada en la Argentina. №5, Buenos Aires, 2006.

HELLER, Ágnes La teoría marxista de la revolución y la revolución de la vida cotidiana. In: La revolución de la vida cotidiana. Barcelona: Península, [1965] 1994.

Sociología de la vida cotidiana. Barcelona: Península, [1970] 1998.

LECHNER, Norbert. Estudiar la vida cotidiana, Los patios interiores de la democracia. Subjetividad y política. Santiago de Chile: FCE, 1990.

LEFEBVRE, Henri. El marxismo sin mitos. Buenos Aires: A. peña Lillo Editor, 1967.

. La vida cotidiana en el mundo moderno. Madrid: Alianza, [1968] 1984.

MARTÍNEZ, Paola. Género, política y revolución en los años setenta. Las mujeres del PRT-ERP. Buenos Aires: Imago Mundi, 2009.

MOLLOY, Sylvia. Relecturas: la huella del género. In: YUDERKYS, Espinosa Miñoso (Coord.) Aproximaciones críticas a las prácticas teórico-políticas del feminismo latinoamericano. V. I. Buenos Aires: En la frontera, 2010.

OBERTI, Alejandra. Género, política y violencia. Vida cotidiana y militancia en los años sesenta y setenta. Tesis de doctorado- MIMEO. Buenos Aires, 2011.

8/9, Buenos Aires, 2008.

PITTALUGA, R. Rawson y Trelew. In: Políticas de la memoria. $n^{\circ} 8 / 9$, Buenos Aires, 2008.

POZZI, Pablo. Por las sendas argentinas: El PRT-ERP. la guerrilla marxista. Buenos Aires: Imago Mundi, 2004. 
RICHARD, Nelly. Género. In: ALTAMIRANO, Carlos (comp.) Términos críticos de sociología de la cultura. Buenos Aires: Paidós, 2002.

SARLO, B. Tiempo pasado. Cultura de la memoria y giro subjetivo. Una discusión. Buenos Aires: Siglo XXI, 2005.

SCHMUCLER, Héctor. El testimonio de los sobrevivientes. Controversia. № 9-10, México, 1980.

SCOTT, Joan W. El género: Una categoría útil para el análisis histórico. In: Cangiano, M. C.; DUBOIS, L. De mujer a Género, teoría, interpretación y práctica feminista en las ciencias sociales. Buenos Aires: CEAL, 1996.

VEZZETTI, H. Sobre la violencia revolucionaria. Memorias y olvidos. Buenos Aires: Siglo XXI, 2009.

Dossiê:

Recebido em: Março/2013

Aceito em: Maio/2013 